Industrial Health, 1980, 18, 195.

\title{
SIMPLIFIED ASSAY METHOD FOR 3-HYDROXYANTHRANILIC ACID IN HUMAN URINE BY FLUOROMETRY AND ITS NORMAL VALUE
}

\author{
Masayasu MINAMI $\dagger$, Kazuko MORI $\dagger$, Takeo TABUCHI ${ }^{\dagger}$ \\ and Ichiro HARAt†
}

\author{
$\uparrow$ National Institute of Industrial Health, 21-1, 6-chome, Nagao \\ Tama-ku, Kawasaki 213, Japan \\ †Osaka Prefectural Institute of Public Health, 3-69, 1-chome, Nakamichi, \\ Higashinari-ku, Osaka, 537, Japan
}

Received August 29, 1980)

\begin{abstract}
Estimations of human exposure levels to aromatic nitro- and amino-compounds (ANA) are often made by Bratton-Marshall's diazo reaction. In Japan, the environmental conditions of the ANA industries have recently improved remarkably. The workers in ANA plants excrete somewhat higher levels of diazotizable substances in the urine than healthy controls and the contributory ratio of the exposed ANA substances to the total diazotizable ones in the urine appears to be of the order of 10 to $20 \%$, most of the time.

Under such circumstances, it is necessary to measure the contributory ratio of physiological ANA substances such as hydroxyanthranilic acid to the total diazotizable substances. A simplified assay method for hydroxyanthranilic acid in the urine was devised employing cation exchanging resins for the separation of the hydroxyanthranilic acid from other contaminating substances in the urine, and using fluorometry in alkaline solution for intensifying the fluorescence of hydroxyanthranilic acid.
\end{abstract}

The reproducibility of the fluorimetric method was tested by an enzymatic assay method for hydroxyanthranilic acid determination in human urine, and the correlation coefficient was satisfactorily high $(\mathbf{r}=0.890, \mathrm{p}<0.01)$. The normal excretory value of hydroxyanthranilic acid in the human urine ranges from 1.71 to 11.2 $(\mu \mathrm{g} / \mathrm{min})$, which is equivalent to 10 to $70 \mu \mathrm{moles} / \mathrm{day}$.

The diazo colour development in body fluids such as the urine, blood, etc. by the Bratton-Marshall reaction, ${ }^{1)}$ is enhanced after intake of aromatic nitro- and aminocompounds (ANA) of medical or industrial use. Examples of the former are aspyrine and pyramidone, and of the latter are aniline and nitrobenzene. Urine samples from normal subjects develop a faint red-purple tint by the Bratton-Marshall diazo reaction ${ }^{12}$. Such colour development of normal urine after the diazo-reaction is due to physiological diazotiziable ANA compounds such as 3-hydroxyanthranilic acid (3-OHAA) which is one 


\section{MINAMI, K. MORI, T. TABUCHI AND I. HARA}

of tryptophan metabolites, kynurenine, xanthurenic acid, indole derivatives, etc. ${ }^{2) 3}$ The Bratton-Marshall reaction is a relevant method for monitoring the degree of ANA exposure $^{4) 5)}$ of workers in the ANA industries.

The current exposure conditions in the Japanese ANA industries have been found to give 0.3 to 2.0 ( $\mathrm{mg} / \mathrm{mg}$ of creatinine) of diazotizable substances (paminophenol (PAP) being used as the calibration standard) in the workers' urine ${ }^{5)}$. The already present physiological diazo value (the normal value) ranges from 0.17 to 0.45 ( $\mathrm{mg} / \mathrm{mg}$ of creatinine $)^{4) 5)}$. Current evidence regarding urinary total diazotizable substances, thus, mean that estimations of the ANA workers' exposure levels by the diazo-reaction may lead to some obscurity. One method for obtaining accurate estimates of A NA exposure levels using a simple detecting reaction like the Bratton-Marshall reaction, would be to evaluate the contribution of physiological diazotizable substances (such as 3-OHAA) with employing another biochemical assay method which gaves the estimate of the physiological diazo value in addition to the Bratton-Marshall reactions and then to subtract the former physiological value from the total value. There is an evidence that hydroxyanthranilic acid reduces methemoglobin, ${ }^{5)}$ which is increased by heavy exposure to ANA substances. A simplified and accurates assay method for 3-hydroxyanthranilic acid is thus desired.

\section{Methods}

\section{Reagents:}

Cation exchanging resin, Dowex $50 \mathrm{~W} \times 2$, was purchased from Sigma Chemicals Ltd. D,L-Tryptophan, kynurenic acid, D,L-3-hydroxytrypophan, indole-3-carboxyaldehyde, and D,L-kynurenin sulfate were purchased from Wako Pure Chemicals Company. 3-Hydroxyanthranilic acid (3-OHAA) was obtained from Nakarai Chemicals Company. All reagents used were of analytical grade, unless indicated otherwise.

\section{Preparation of the column:}

Dowex $50 \mathrm{~W} \times 2$ was subspended in glass-distilled and deionized water (water) overnight, washed several times with water, $2 \mathrm{~N} \mathrm{HCl}$, water, $2 \mathrm{~N} \mathrm{NaOH}$ and water. This serial washing was repeated twice. The resin was then resuspended in water until use. The washed Dowex resin was poured into a glass column (Fig. 1) of $0.7 \mathrm{~cm}$ in diameter, until the resin reached a height of $4 \mathrm{~cm}$. The column had a reservoir and was plugged with glass wool.

\section{Application of the urine somple to the column:}

The column was washed twice with 2 volumes to $0.1 \mathrm{~N} \mathrm{HCl}$ before applying the sample to it. Ten to $20 \mathrm{~m} l$ of urine sample was diluted to $40 \mathrm{~m} l$ by adding water and $\mathrm{HCl}$ solution, the final concentration of which was adjust to 0.1 molar in the diluted sample. The diluted urine sample containing 0.1 molar $\mathrm{HCl}$ was then applied to the column. 


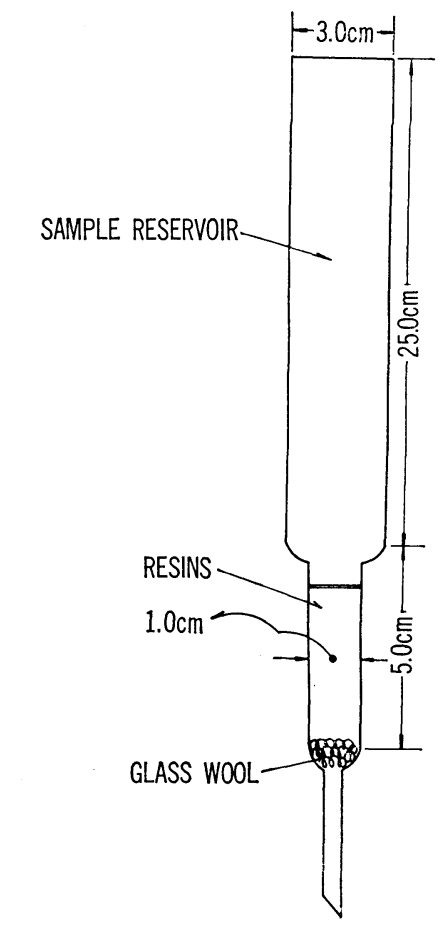

Fig. 1. Column for separation of 3hydroxyanthranilic acid from human urine samples.

\section{Apparatus :}

An Hitachi MPF4 spectrofluorometer, Cary 14 and Hitachi 101 spectrophotometers were used for the study. Water at $37^{\circ} \mathrm{C}$ was made to circulate around the cell chamber of the spectrophotometer, from a water bath equipped with a thermostat, when the enzymatic assay was performed.

\section{Enzymatic assay:}

An enzymatic assay method for 3-OHAA was established by referring to the papers of Ishiguro et al. ${ }^{7)}$ and Savage and Prinz ${ }^{8)}$. The detailed procedure of the enzymatic method will be published elsewhere. Only a summary of the method, for comparison with the fluorimetric method, is given here.

The reaction mixture consisted of $0.1 \mathrm{~m} l$ of $40 \mathrm{mM} \mathrm{MnCl}_{2}, 0.2 \mathrm{ml}$ of $1 \mathrm{mg} / \mathrm{ml}\left(\mathrm{H}_{2} \mathrm{O}\right)$ catalase, $0.5 \mathrm{~m} l$ of $2 \mathrm{mM}$ hypoxanthine, $0.2 \mathrm{~m} l$ of sample and $0.1 \mathrm{M}$ sodium phosphate buffer ( $\mathrm{pH} 7.40$ ) added to make the volume of the medium up to $4.0 \mathrm{~m} l$. The enzyme reaction was initiated by adding $50 \mu l$ of xanthine oxidase solution (in the ammonium sulfate solution used directly from the purchased bottle). 


\section{MINAMI, K. MORI, T. TABUCHI AND I. HARA}

\section{Normal value measurement :}

Three healthy office clerks were requested to void urine 3 to 5 times during the working period for 3 days, and 5 university students were also requested to do the same. Each urine sample was transferred immediately to a polyethylene bottle containing $0.5 \mathrm{~m} l$ of concentrated $\mathrm{HCl}$ and the sample was frozen in a refrigerator $\left(-40^{\circ} \mathrm{C}\right)$ until assay.

\section{Results AND Discussion}

For the analysis of 3-OHAA in the biological fluids, the following steps of analysis were followed: (1) separation and purification, and (2) identification. The separation was performed by column chromatography with Dowex $50 \mathrm{~W} \times 2$ and 3-OHAA was identified by fluorometry in alkaline solution.

(1) Elution pattern of 3-OHAA from the column:

Ten to $20 \mathrm{~m} l$ of urine was acidified with $\mathrm{HCl}$ and diluted to $40 \mathrm{~m} l$ with water as described under method. The sample was then applied to the column. When the sample had passed through the column, consecutive addition to the column of $50 \mathrm{~m} l$ of $0.1 \mathrm{M}$ $\mathrm{HCl}, 100 \mathrm{~m} l$ of $0.2 \mathrm{M} \mathrm{HCl}$ and $100 \mathrm{~m} l$ of $1.0 \mathrm{M} \mathrm{HCl}$ was made, and a final addition of a $1 \mathrm{M} \mathrm{HCl}$ aliquot was used for the determination of 3-OHAA in the urine. The elution pattern of the human urine sample with authentic 3-OHAA added was the same as that of the authentic 3-OHAA solution (Fig. 2). The fraction eluted from the column with $1 \mathrm{M} \mathrm{HCl}$ had the same excitation $(315 \mathrm{~nm})$ and emission $(390 \mathrm{~nm})$ fluorescene peaks as the authentic 3-OHAA after the addition of $2 \mathrm{M} \mathrm{NaOH}$ to the aliquot. The elution pattern was the same as that in Tompsett's reports ${ }^{9 a, b)}$.

The elution speed was $2.0 \mathrm{ml} / \mathrm{min}$. Fig. 3 shows the relation between the fluorescence intensity and $\mathrm{pH}$ of the solvent containing the 3-OHAA fraction from the Dowex column

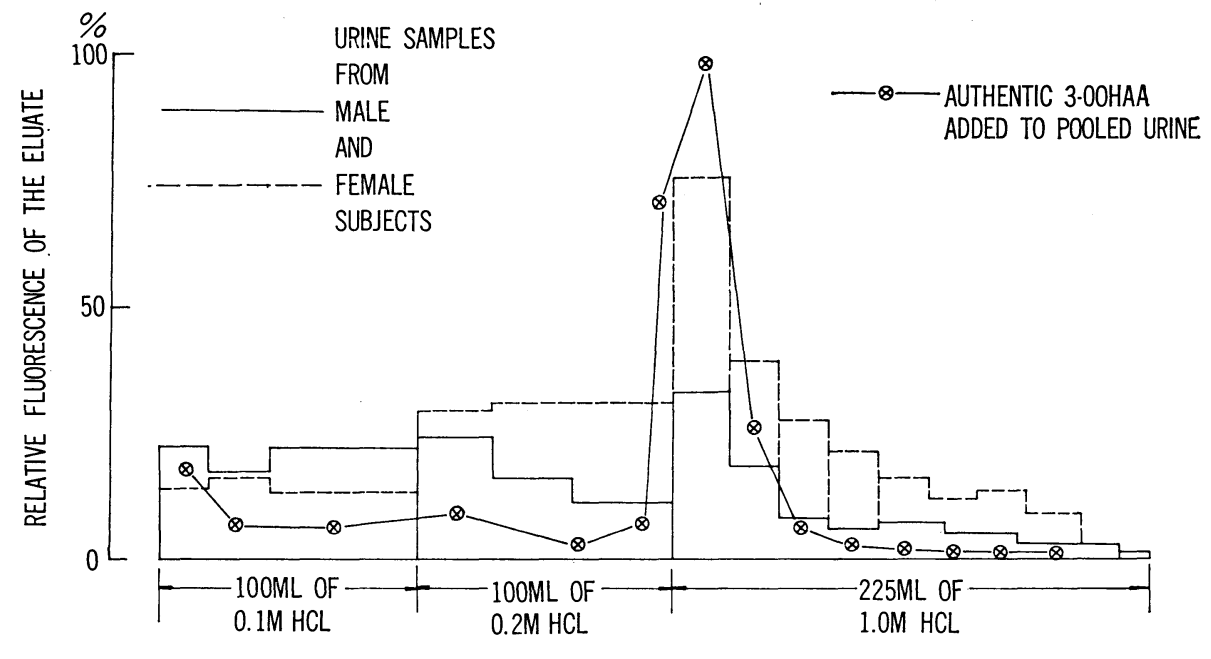

Fig. 2. Elution pattern of 3-hydroxyanthranilic acid from the Dowex $50 \mathrm{~W} \times 2$ column $\left(\mathrm{H}^{+}\right.$type). 


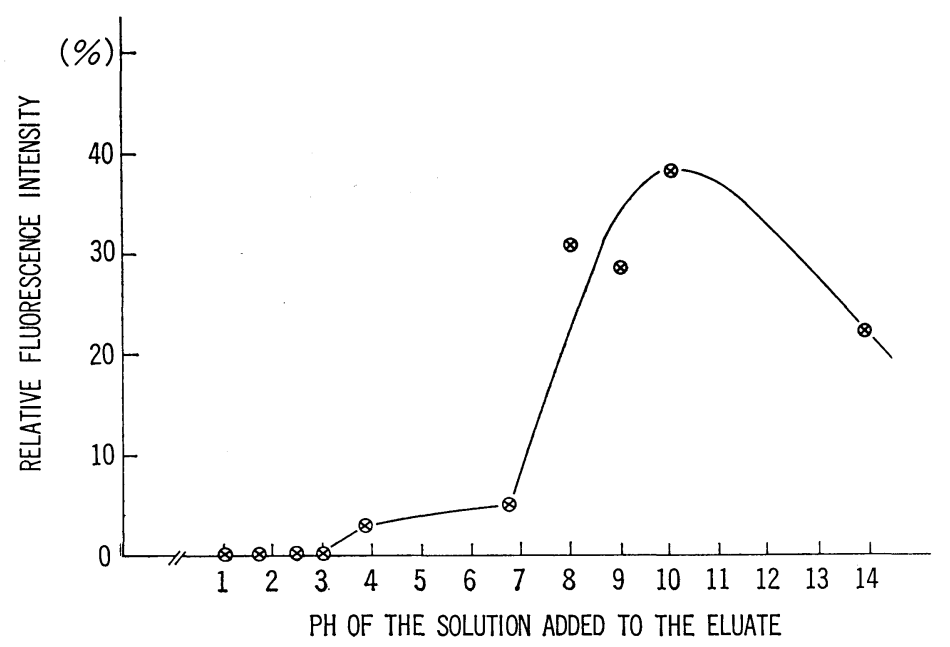

Fig. 3. The pH-fluorescence relation.

Numbers on the abscissa indicate the $\mathrm{pH}$ of the solution which was added to the aliquot of the eluate from the column.

( $\mathrm{pH}$-fluorescence relation). It is well-known that the fluorescence intensity of a substance depends closely upon the solvent's $\mathrm{pH}^{10)}$. Detailed examination of the 3-OHAA fluorescence in solvents of different $\mathrm{pH}$ 's revealed that the 3-OHAA fluorescence was intensified in a solvent of alkaline $\mathrm{pH}$. The fluorescence intensity was measured at $315 \mathrm{~nm}$ excitation and $390 \mathrm{~nm}$ emission wavelengths. The measurements of the $\mathrm{pH}$-fluorescence relation was made by the following procedure. Two volumes of the buffer were added to one volume of the eluate, or 3-OHAA in $1 \mathrm{M} \mathrm{HCl}$. The buffers used in the study are listed in Table 1. All of the solute concentrations in the buffer were made 0.1 molar. Maximum fluorescence of 3-OHAA in $1 \mathrm{M} \mathrm{HCl}$ after the addition of 2 volumes of the buffer was obtained, when $0.1 \mathrm{M}$ borate buffer $(\mathrm{pH} 10.0)$ was added to the sample. Alkaline buffer caused the fluorescence of 3-OHAA to be intensified. For convenience

Table 1. Relative fluorescence intensity of 3-OHAA at different $\mathrm{pH}$ 's of the medium.

\begin{tabular}{clc}
\hline $\mathrm{pH}$ & \multicolumn{1}{c}{ Buffer used } & Relative fluorescence intensity (\%) \\
\hline $1.00>$ & $\mathrm{HCl}$ & 0.00 \\
1.88 & pyrophosphate & 0.00 \\
2.48 & glycine & 0.00 \\
3.00 & barbiturate & 0.05 \\
3.89 & acetate & 0.29 \\
6.98 & phosphate & 4.90 \\
8.00 & triethanol amine & 31.0 \\
9.00 & tris-hydroxymethylaminomethane & 28.7 \\
10.0 & borate & 38.0 \\
$14.0<$ & NaOH & 21.5 \\
\hline
\end{tabular}




\section{MINAMI, K. MORI, T. TABUCHI AND I. HARA}

of the measurement, $2.0 \mathrm{M} \mathrm{NaOH}$ was adopted for routined 3-OHAA assay.

The relative fluorescence intensity ratio of a certain substance to the 3-OHAA fluorescence intensity after addition of $2 \mathrm{M} \mathrm{NaOH}$ to the sample in $1.0 \mathrm{M} \mathrm{HCl}$ was measured. The results are shown in Table 2. Separation of anthranilic acid from 3-

Table 2. Relative fluorescence intensity of different substances related to tryptophan metabolism, as compared to that of 3-hydroxyanthranilic acid.

\begin{tabular}{lc}
\hline \multicolumn{1}{c}{ Substance } & $\begin{array}{r}\text { Fluorescence intensity relative to } \\
\text { 3-OHAA in } 2 \mathrm{M} \mathrm{NaOH}\end{array}$ \\
\hline 3-hydroxyanthranilic acid & 1.00 \\
3-hydroxypyridine & 0.37 \\
anthranilic acid & 0.88 \\
kynurenine & 0.048 \\
xanthrenic acid & 0.072 \\
kynurenic acid & 0.059 \\
D,L-tryptophan & 0.0098 \\
p-aminohippuric acid & 0.12 \\
pyridoxal phosphate & 1.20 \\
\hline
\end{tabular}

The excitation wavelength was $315 \mathrm{~nm}$ and the emission wavelength was $390 \mathrm{~nm}$ (Hitachi MPF-4 spectrofluorometer).

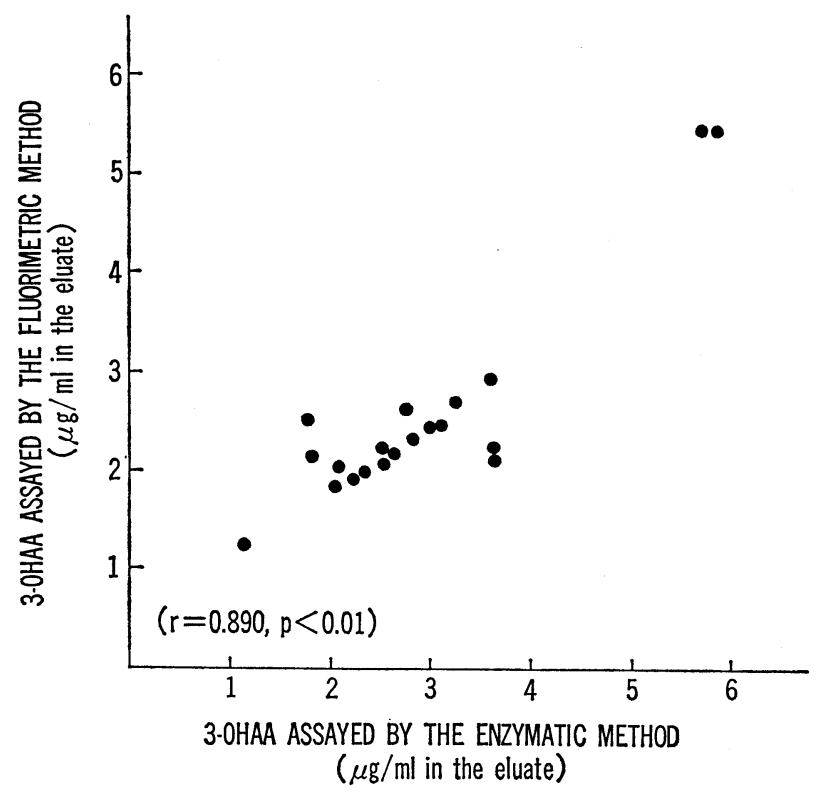

Fig. 4. Test of the reproducibility of the fluorimetric assay. An enzymatic assay method was adopted for com. parison with the fluorometric assay (see text). 


\section{ASSAY OF 3-OHAA IN HUMAN URINE}

OHAA was not possible by this method. In the eluted fraction in $1.0 \mathrm{M} \mathrm{HCl}$, therefore, after the addition of $2 \mathrm{M} \mathrm{NaOH}$, both 3-OHAA and anthranilic acid (AA) emit the same intensity of fluorescence per molar concentration at the selected emission and excitation wavelengths. With human urine, however, the effect of contaminant AA was negligible, since only trace of AA, at most is excreted quantitatively as its glycine or glucuronic acid conjugates ${ }^{11) 12}$, which were eluted from the Dowex column in the previous fractions.

The recovery rate of the authentic 3-OHAA added to the column ranged 75.0 to $81.0 \%$, and the coefficient of variance (C.V.) was $1.23 \%$ (the sample numbers were 50 and the added 3-OHAA ranged from 200 to $500 \mu \mathrm{g} / 100 \mathrm{ml}$ ). The C.V. was sufficiently small.

The reproducibility of the assay method for 3-OHAA required testing by using another assay method for 3-OHAA. The catalase manganese coupling cinnabarinic acid condensation reaction ${ }^{7 / 8)}$ was selected as the test, since the two assay systems are basically different from each other. The results compiled were in good agreement with each other between 2.0 and $5.5 \mu \mathrm{g}$ of $3-\mathrm{OHAA}$ in $1.0 \mathrm{ml}$ of the medium. The correlation coefficient was statistically significant $(\mathrm{r}=0.890, \mathrm{P}<0.01 ;$ Fig. 4$)$. The enzymatic method tends to give somewhat lower estimates for concentration of 3-OHAA. That

Table 3. Urinary excretion of 3-hydroxyanthranilic acid in healthy male subjects $(\mu \mathrm{g} / \mathrm{min})$.

\begin{tabular}{|c|c|c|c|c|c|c|c|c|c|c|c|}
\hline \multirow{4}{*}{\multicolumn{2}{|c|}{ Time }} & \multicolumn{10}{|c|}{ Day when sample was taken } \\
\hline & & \multicolumn{4}{|c|}{23 April, 1979} & \multicolumn{3}{|c|}{24 April, 1979} & \multicolumn{3}{|c|}{25 April, 1979} \\
\hline & & \multicolumn{10}{|c|}{ Name (age) } \\
\hline & & \multicolumn{4}{|c|}{ I.N. (65 yrs) } & \multicolumn{3}{|c|}{ T.D. (53 yrs) } & \multicolumn{3}{|c|}{ M.Z. (28 yrs) } \\
\hline \multicolumn{2}{|c|}{$\begin{array}{l}8: 00 \text { to } \\
9: 00 \text { a.m. }\end{array}$} & & 66 & - & 4.53 & 5.31 & 5.01 & 7.77 & 2.90 & 5.31 & 5.77 \\
\hline \multicolumn{2}{|c|}{$11: 00$ a.m. } & & 33 & - & 5.63 & 6.06 & 7.87 & 4.47 & 2.17 & 3.50 & 3.60 \\
\hline \multicolumn{2}{|c|}{$13: 00$ p.m. } & & 45 & - & 7.17 & 9.60 & 8.50 & 5.77 & 3.82 & 2.93 & 3.46 \\
\hline \multicolumn{2}{|c|}{$15: 00$ p.m. } & & 39 & 2.51 & 8.26 & 10.80 & 11.20 & 4.96 & 3.61 & 2.95 & 2.45 \\
\hline \multicolumn{2}{|c|}{$16: 30$ p.m. } & & 18 & 3.88 & 7.92 & 11.10 & 6.42 & 3.50 & 3.40 & 4.51 & 3.00 \\
\hline \multirow{2}{*}{\multicolumn{2}{|c|}{ Time }} & \multicolumn{10}{|c|}{ Name (age) } \\
\hline & & \multicolumn{3}{|c|}{ H.D. (20 yrs) } & \multicolumn{2}{|c|}{ K.W. (20 yrs) } & \multicolumn{2}{|c|}{ O.N. (20 yrs) } & H.Y. (21 yrs) & \multicolumn{2}{|c|}{ Y.N. (21 yrs) } \\
\hline \multirow[t]{4}{*}{$9: 00$ to } & \multicolumn{2}{|c|}{$9: 45$ a.m. } & & 7.50 & \multicolumn{2}{|c|}{11.10} & \multicolumn{2}{|c|}{1.71} & 2.19 & \multicolumn{2}{|c|}{4.36} \\
\hline & \multicolumn{2}{|c|}{$11: 35$ a.m. } & & 4.40 & \multicolumn{2}{|c|}{8.48} & \multicolumn{2}{|c|}{2.41} & 9.07 & \multicolumn{2}{|c|}{5.60} \\
\hline & \multicolumn{2}{|c|}{$13: 15$ p.m. } & & 7.20 & \multicolumn{2}{|c|}{2.56} & \multicolumn{2}{|c|}{3.00} & 2.61 & \multicolumn{2}{|c|}{9.83} \\
\hline & \multicolumn{2}{|c|}{$15: 25$ p.m. } & & 7.70 & \multicolumn{2}{|c|}{6.57} & 5.29 & & 4.27 & & .70 \\
\hline
\end{tabular}

Data from office clerks are shown in the upper part of the table; those in the lower part are from students. The estimation shown in the upper part of the table was performed for three consecutive day per a person. 


\section{MINAMI, K. MORI, T. TABUCHI AND I. HARA}

may be due partly to absorbance change of the flavin enzyme, xanthine oxidase. Confirmatory experiments on this point are now in progress.

The excretory rate of 3-OHAA into the urine of healty male subjects ranged from 1.71 to $11.2 \mu \mathrm{g} / \mathrm{min}$, as shown in Table 3 . These urinary excretory values were equivalent to 10 to $70 \mu$ moles/day, which was within the reported normal range of urinary values for $3-\mathrm{OHAA}^{1112)}$.

\section{REFERENCES}

1) Bratton, C. and Marshall, E.K. Jr. (1939). J. Biol. Chem., 128, 537.

2) Brown, R.R. and Price, J.M. (1956). J. Biol. Chem., 219, 985.

3) Dalgliesh, C.E. (1955). Biochem. J., 61, 334.

4) Watanabe, T., Ishihara, N. and Ikeda, M. (1976). Int. Arch. Occup. Environ. Health, 37, 157.

5) Goda, K., Ueda, T. and Kotake, Y. (1979). Proceedings of Intal. Congress of Biochemistry, 1979, FP-33.

6) Ishiguro, I., Nagamura, Y. and Hara, A. (1971). Yakugaku Zasshi, 91, 760. (in Japanese).

8) Savage, N. and Prinz, W. (1977). Biochem. J., 161, 551.

9a)Tompsett, S.L. (1959). Clin. Chim. Acta, 4, 411.

9b) Tompsett, S.L. (1959). Clin. Chim. Acta, 5, 415.

10) Udenfriend, S. (1969). Fluorescence Assay in Biology and Medicine, Vol. II, p. 204, Academic Press' New York and London.

11) Michel, A.F., Drummond, K.N., Doeden, D., Anderson, J.A. and Good, R.A. (1964). J. Clin. Invest., 43, 1970.

12) Price, J.M., Brown, R.R. and Yess, N. (1965). Adv. Metabol. Disorders, 2, 159. 